\title{
UN PROGRAMA DE EXALTACIÓN MARIANA EN LA IGLESIA DE SANTA MARÍA LA BLANCA DE SEVILLA
}

\author{
A MARIAN EXALTATION PROGRAM AT THE SANTA MARIA LA BLANCA \\ CHURCH IN SEVILLE.
}

\author{
Juan Carlos Hernández Núñez, Alfredo J. Morales \\ Universidad de Sevilla \\ ORCID: 0000-000 I-6735-I559, ORCID: 0000-000 I-5986-3I 24
}

ABSTRACT • Santa María La Blanca, a medieval Church in Sevilla, was renovated in the XVII century. At that time a unique ornamentation program was developed in light of the brief pontifical in 166labout the immaculate conception of Mary. The restoration in 2015 of its plasterwork and wall paintings has allowed the recovery of the images and texts of its program, an iconographic message about Marian praise and eucharistic cult that is analyzed in this study.

KEYWORDS: Justino de Neve; Murillo; Faux Plasterwork; Litanies; Baroque Festivity.

RESUMEN • La iglesia medieval de Santa María la Blanca de Sevilla fue renovada durante el siglo XVII, desarrollándose su ornamentación tras el Breve Pontificio de 1661 sobre la concepción inmaculada de María. La restauración en 2015 de las yeserías y pinturas murales de su interior ha permitido recuperar las imágenes y textos del programa de exaltación mariana que, junto al culto eucarístico, integran su mensaje iconográfico.

PALABRAS CLAVES: Justino de Neve; Murillo; Yeserías fingidas; Letanías; Fiesta barroca. 
Considerada como una de las cimas del arte español del Barroco, la sevillana iglesia de Santa María la Blanca ha despertado el interés de los investigadores, siendo abundantes las publicaciones que la han tratado. La primera de las aportaciones corresponde a Fernando de la Torre Farfán quien en 1666 describió en un libro las fiestas en honor de la Inmaculada y el Santísimo Sacramento celebradas por la consagración del templo, tras el Breve Pontificio de Alejandro VII del 8 de diciembre de 1661. La más reciente, un artículo de Recio Mir (2015), que aborda su interpretación a partir de la coyuntura artística de la ciudad, de la personalidad de Justino de Neve, de las pinturas e inscripciones de sus muros, del mencionado libro de Torre Farfán y del sermón pronunciado por el capellán real Pedro Francisco Levanto durante la novena que siguió a la consagración. Entre ambas hay variedad de estudios de diferente entidad y objetivos que han destacado aspectos concernientes a la historia del inmueble. Muchas de tales aportaciones son de mediados del siglo XX, si bien han sido más numerosas en las últimas décadas del presente (Falcón Márquez 1988; 2011; 2012; 2015; Bonet Correa, 1978; Arenillas, 2005; Roda Peña, 2012). Entre éstas cabe mencionar las surgidas tras la restauración del edificio, con propuestas y conclusiones que han suscitado el rechazo de algunos investigadores (Gil Delgado 2013a; 2013b; Cómez, 2015). La suma de trabajos permite contar con una información amplia, aunque todavía incompleta, sobre la historia y los valores del templo [fig. 1].

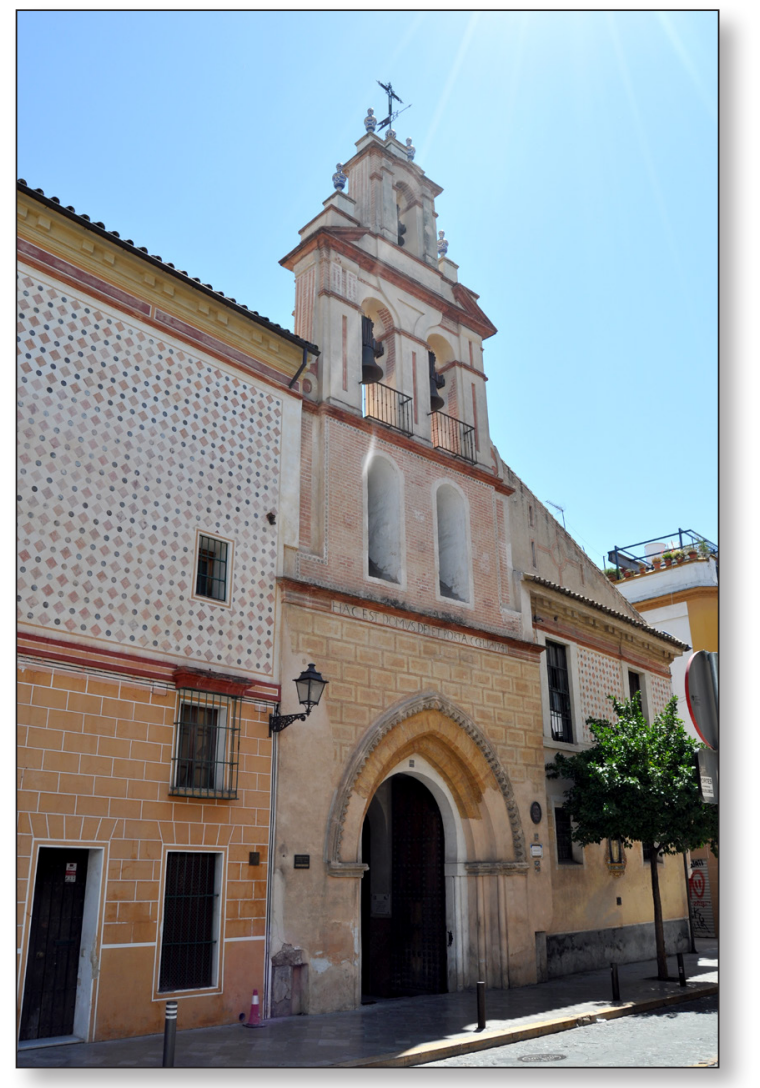

Fig. 1. Iglesia de Santa María la Blanca. Sevilla. 
La actual iglesia de Santa María la Blanca fue en origen una mezquita, convertida posteriormente en sinagoga, que luego pasó a ser templo cristiano. El edificio es sustancialmente el mismo, aunque con cambios en su orientación y fisonomía según las necesidades cultuales y el gusto artístico de cada etapa. El templo medieval fue transformado durante el siglo XVII, aunque manteniendo lo esencial de su estructura, añadiéndosele capillas y la sacristía a la nave de la Epístola, levantándose la espadaña y rehaciéndose la capilla mayor (Arenillas, 2005: 176; Falcón Márquez, 2012: 63). Pero el momento clave de la transformación se produjo a raíz del Breve Pontificio antes mencionado, cuando el canónigo don Justino de Neve, responsable de las capillas dependientes de la catedral sevillana, emprendió como tarea personal y sufragándola en buena medida la renovación del templo. Dicha labor es testimonio de su devoción y amor a la Inmaculada Concepción, siendo también expresión de la exaltación religiosa que vivía la ciudad y que se tradujo en la riqueza decorativa que engalanó los templos. Para llevar a cabo el programa constructivo Neve encomendó en 1662 los trabajos de arquitectura al maestro Juan González, contando con Murillo para la realización de las pinturas sobre lienzo que son claves para el mensaje que encierra la iglesia, atribuyéndose a este maestro el diseño y dirección de la realización de las pinturas murales y señalándose a Alonso Pérez como su posible autor material (Falcón Márquez, 2012: 61; 2015: 91). En ese proceso de modernización se inscribe la realización de las blancas yeserías -clara referencia a la titular del templo y a las nieves que dieron origen a la basílica romana de Santa María la Mayor, cuya historia se recoge en los lienzos del falso crucero, sin olvidar la coincidencia del apellido del promotor y la blancura de la nieve- que transforman la arquitectura junto con las pinturas murales mediante un teatral juego que combina realidad y apariencia, haciendo de este interior uno de los más bellos y fascinantes de la arquitectura barroca andaluza. La iglesia fue inaugurada con gran boato festivo el 5 de agosto de 1665, tras haberse completado su programa decorativo.

La reciente restauración de las yeserías y pinturas murales que enriquecen las bóvedas del presbiterio y de las tres naves y los paramentos perimetrales ha facilitado el acceso a estos elementos ornamentales y a la lectura de las inscripciones latinas que se intercalan con las últimas ${ }^{1}$. Ciertamente en anteriores publicaciones se habían recogido parte de ellas, pero las dificultades de su visualización y el mal estado de conservación habían complicado la transcripción y comprensión de los textos (Falcón Márquez, 1991; 2013: 266; 2015: 93 96; Recio Mir, 2015: 193-196). Es más, tampoco durante el aludido proceso de restauración ha sido posible recogerlos en su totalidad, pues la presencia de retablos incorporados al patrimonio mueble del templo con bastante posterioridad a la terminación de las pinturas oculta varias cartelas. Además, otras inscripciones no ha sido posible recuperarlas al haber perdido sus textos. A pesar de estas carencias, es posible restituir el programa en el que dichas leyendas servían de complemento a los símbolos y motivos figurativos de evidente sentido mariano. Por otra parte, la aludida restauración ha permitido conocer cuestiones técnicas sobre la materialidad de dichas pinturas y su proceso de ejecución, que serán dados a conocer próximamente.

Las aludidas pinturas murales del interior del templo, con independencia de sus valores artísticos y su cuidada ejecución para asimilarse a los yesos de las bóvedas, constituyen, como ya indiqué, el precedente más directo del progresivo abandono de las labores en yeso en los

1. El proyecto y la dirección técnica correspondieron a Juan Manuel Macías Bernal y Fátima Domínguez Fernández, realizando los trabajos la empresa Ágora. Restauraciones de Arte. S.L. dirigida por Juan Aguilar Gutiérrez y Bárbara Hasbach Lugo. Juan Carlos Hernández Núñez, uno de los autores de este texto, formó parte del equipo multidisciplinar constituido para llevar a cabo la restauración. 
interiores religiosos sevillanos de la última década del Seiscientos, en beneficio de los grandes ciclos pictóricos (Morales, 2009: 149). En un magistral juego de apariencias o de engaño entre materiales y técnicas característico del Barroco, la suma de yeserías y pinturas contribuye a crear un espacio misterioso y fascinante que impacta y emociona al espectador y mueve su ánimo, trasladándolo al mundo trascendente y acercándolo a los misterios de la fe. En este caso a la condición inmaculada de María, como pregonan las frases dispuestas en la rosca del arco del coro, tanto en su frente, como por su interior: «Sin pecado original en el primer instante de su ser». Se trata de la única frase castellana del conjunto y funciona como resumen o clave del mensaje desplegado en las paredes del templo, pues facilita su comprensión a los fieles carentes de conocimientos del latín en las que están escritas las restantes inscripciones, aunque podían deducirlas por los inmediatos símbolos marianos [fig. 2].

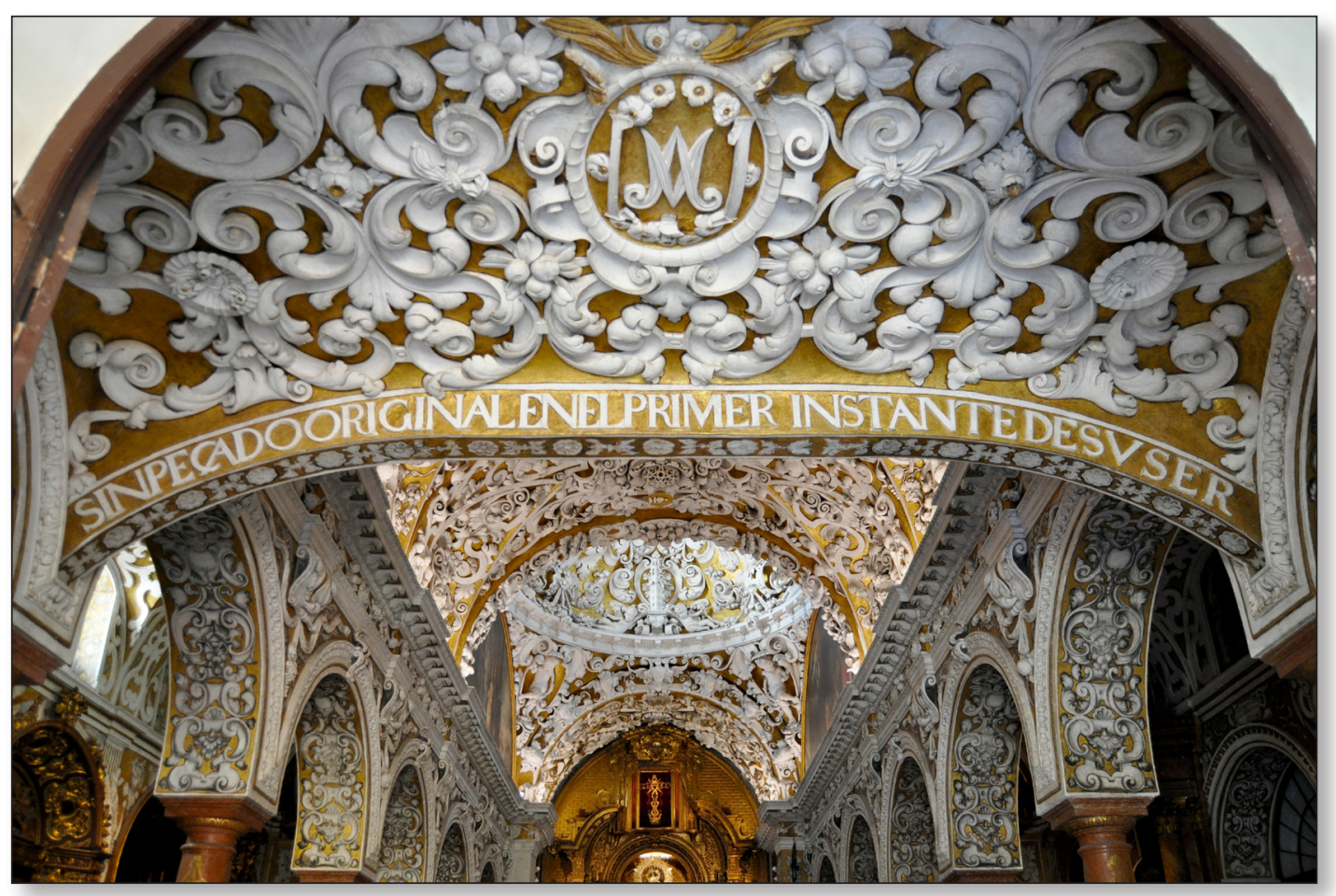

Fig. 2. Vista general. Sotocoro.

La extraordinaria riqueza y calidad de las yeserías que recubren las bóvedas de la iglesia, que no es momento de tratar, tienen su efectista contrapunto en las pinturas murales que fingen ser auténticas labores en yeso gracias al sombreado con negro. Están pintadas en blanco, destacando poderosamente sobre el dorado que constituye el fondo de toda la ornamentación del templo. Aparecen desplegadas por los muros perimetrales y sobre los arcos y enjutas de las naves laterales, adornando también el intradós de dichos arcos. En las paredes se disponen sobre el alto zócalo de azulejos de motivos en blanco y azul que se considera obra del ceramista Diego de Sepúlveda (Falcón Márquez, 2015: 97). Las pinturas están constituidas por un movido conjunto de roleos y gruesos tallos vegetales rematados en 
cogollos, sobre los que cabalgan o se intercalan figuras infantiles. Tales motivos, que recuerdan algunos de los grabados del francés Jean Le Pautre, se organizan a lo largo de los muros laterales en composiciones simétricas interrumpidas a trechos para situar las cartelas con los símbolos marianos y los textos latinos. Las de formato rectangular son registros bordeados por festones de hojas ceñidas por cintas, un querubín en la base, enmarque con motivos de enrollamiento y dos ángeles tenantes sobre nubes. Las cuadrangulares se flanquean por volutas vegetales, apoyan en temas de enrollamiento y un querubín, rematándose por tres querubines, el central visto de frente y los dos laterales de perfil. Dicha composición se integra entre los roleos y cogollos distribuidos por la pared, coronándose por tarjas ovales con labores de enrollamientos y auriculares, más unas serpenteantes bandas textiles rematadas en borlas. Estas tarjas aparentan ser motivos de incrustaciones y recuerdan piezas de joyería. Responden a un tipo similar los cartuchos dispuestos sobre los arcos y en la embocadura de la capilla bautismal, aunque éste se enriquece con temas auriculares y de enrollamiento, bajo los que se disponen figuras con cuerpos prolongados en gruesos y sinuosos tallos vegetales. Muy parecida es la cartela situada sobre la ventana de la citada capilla, con un marco de potentes volutas con hojarasca y enrollamientos, también empleados en el enmarque del hueco. Los muros de este recinto presentan pinturas con figuras infantiles entre roleos vegetales, variante del modelo empleado en las naves. Es en las cartelas ovales, en las rectangulares y cuadrangulares donde se localizan las inscripciones aclaratorias de los símbolos marianos. Los textos están escritos en mayúsculas latinas doradas, mientras las referencias a las fuentes bíblicas aparecen abreviadas en minúsculas, completándose la ornamentación de la cartela con pequeños ramos o tallos vegetales pintados en negro y algún detalle en dorado [fig. 3].

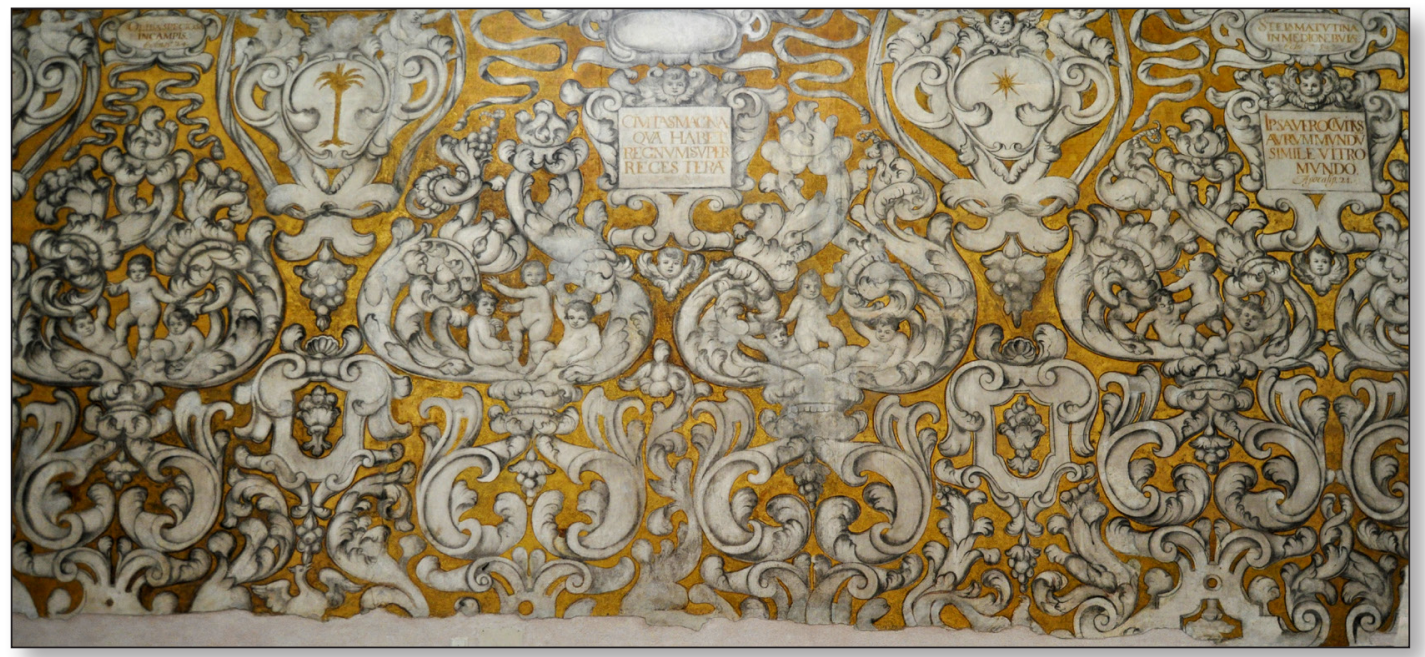

Fig. 3. Motivos decorativos. Nave del evangelio.

Diferentes son las cartelas dispuestas en las enjutas de los arcos y sus simétricas de los muros perimetrales, pues presentan formato aovado. Están enmarcadas por volutas enroscadas o grandes "C»", además de tallos y hojas, presentando en el remate un querubín y una pareja de figuras infantiles entre los tallos y volutas, soportando en una de sus manos una 
banda textil que rodea y se enlaza con la cartela. Bajo ella cuelga una guirnalda de flores y frutas, lo que refuerza su imagen de pieza de joyería ${ }^{2}$. Esas cartelas están a eje de los resaltos del entablamento que apean los arcos fajones, ocupando también las enjutas. Son las que albergan los símbolos marianos, que están pintados en dorado y perfilados en negro, color empleado para los sombreados. En los falsos lunetos de las naves laterales, enmarcadas por roleos con hojas, se han pintado alternativamente jarrones de azucenas y la Giralda, que integran el escudo del cabildo de la catedral sevillana, de la que dependía Santa María la Blanca. En el intradós de los arcos se han pintado querubines, volutas, motivos auriculares y de enrollamiento formando una composición que, a menor escala, se asemeja a las yeserías de los fajones de la nave central. Peculiar es la pintura arquitectónica que queda parcialmente oculta por el retablo de la Piedad, cuyas tablas pintó Luis de Vargas en 1564. Se trata de una fingida estructura a modo de portada con pilastras toscanas acanaladas. Estos falsos elementos portantes están a eje de los resaltos de la cornisa que apean los arcos fajones. Se superponen parcialmente a esas pilastras otras de menor porte rematadas por pirámides sobre esferas, más otra en la cúspide. A la altura de éstas hay un fragmento de entablamento que apoya un frontón, curvo, roto y gallonado con figuras de angelitos sedentes. La composición no resulta simétrica, pues tales elementos cubren parte de la falsa pilastra mayor izquierda, mientras que sobresalen de la derecha. Tal asimetría prueba que este fingido enmarque arquitectónico no se realizó para encuadrar el retablo de la Piedad, ligeramente desplazado respecto al centro del tramo de nave en que se ubica. Esto hace sospechar que para instalar el retablo se aprovechó un hueco anterior a la renovación barroca del templo, probablemente un antiguo acceso lateral que sería cegado al colocar allí el retablo³. Esta operación podría haberse producido en 1774, coincidiendo con la renovación del retablo, momento en el que se le incorporaron las rocallas que presenta [fig. 4].

Respecto a los símbolos marianos de los muros, es evidente que organizan una especie de orla que el fiel puede interpretar como rodeando a la imagen de la Virgen de las Nieves, titular del templo y que preside el retablo mayor. Esta fórmula compositiva responde a la iconografía de la Tota Pulchra, unas palabras que integran el verso Tota pulchra es amica mea, et macula non est in te, del Cantar de los Cantares. Con esta frase se expresa, tal y como se indica en el arco del coro, que Dios preservó a María «sin pecado original en el primer instante de su ser». Así se recoge en la Bula Ineffabilis Deus que proclamó el dogma de la Inmaculada Concepción en 1854, en la que hay palabras semejantes a las utilizadas por Alejandro VII en 1661 en su Bula Sollicitudo omnium Ecclesiarum, que propició la renovación del templo sevillano. No debe extrañar por ello que en el libro de Torre Farfán sobre la fiesta de consagración de la transformada iglesia se vincule a la Virgen de las Nieves con la Inmaculada, una identificación que, como se ha señalado, cabe atribuir a Justino de Neve (Recio Mir, 2015: 192). Él fue también personaje clave en la celebración de las aludidas fiestas de consagración, colaborando decisivamente en la organización de los festejos y prestando pinturas para enriquecer las arquitecturas efímeras que se erigieron. Es el caso del hermoso lienzo de la Inmaculada, excepcional obra de Murillo que presentaba a María conforme a la nueva iconografía propugnada por Pacheco en su Arte de la Pintura. Esto no fue óbice para que en su marco se tallasen símbolos de las letanías, a la manera del tradicional esquema de la Tota Pulchra (Cenalmor Bruquetas, 2012: 114-117; Morales, 2019: 173).

2. Estas guirnaldas son parecidas a las pintadas en el sumoscapo de las columnas de mármol rojizo de las naves.

3. De ser cierta esta hipótesis el ingreso correspondería con el fragmento de arco descubierto en la actual casa parroquial y considerado parte de la galería abierta al patio en la antigua mezquita. Este acceso estaría a eje con el existente en la nave de la Epístola que comunica con la calle Archeros. 

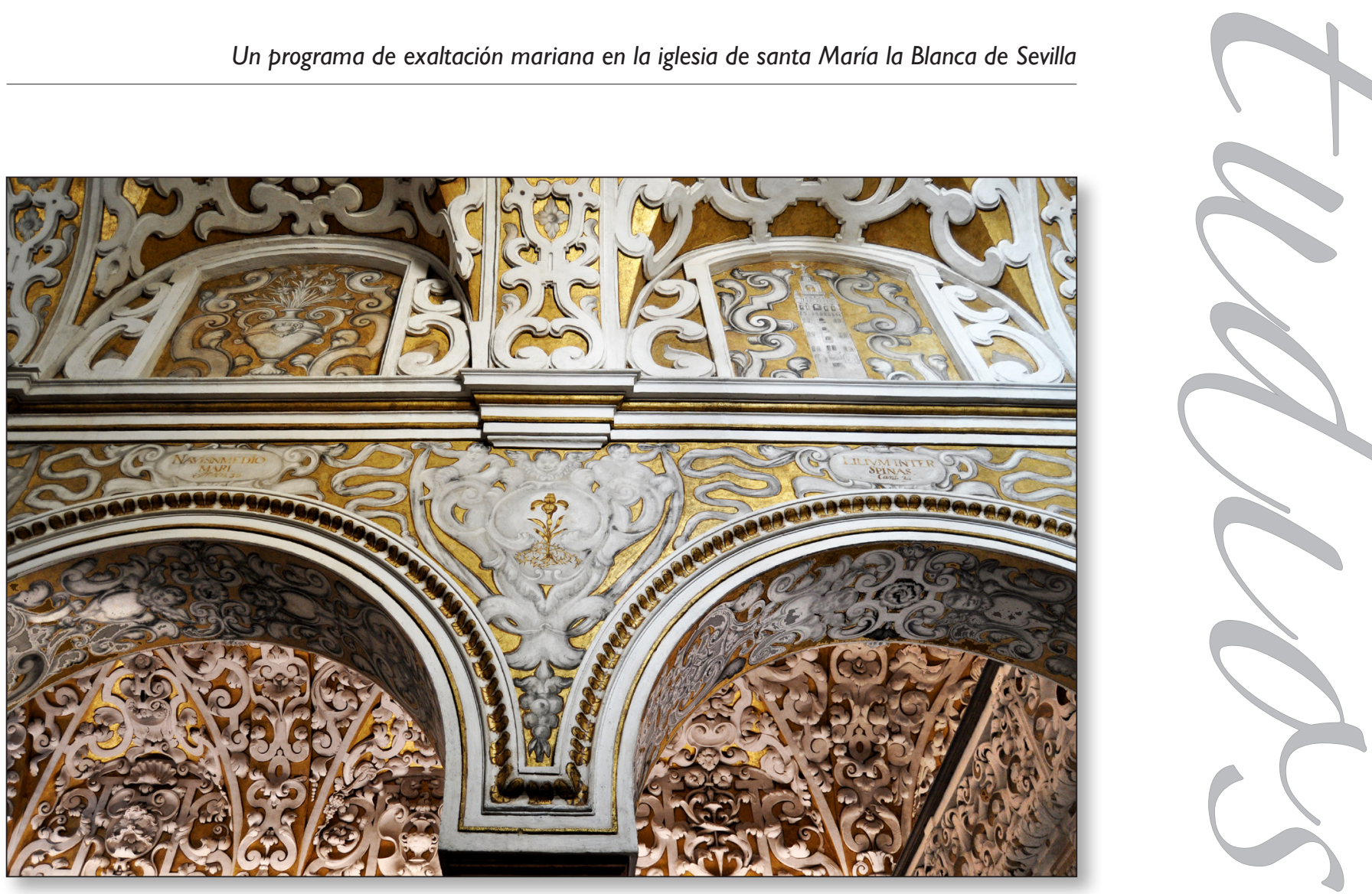

Fig. 4. Enjutas de los arcos formeros.

Los símbolos marianos que aparecen en el interior del templo son en total veintitrés. Corresponden a los más frecuentes de las letanías de la Virgen, aunque también hay alguno menos habitual. Como es bien sabido el conjunto de las letanías marianas son una serie de alabanzas y súplicas que alcanzaron una enorme difusión y evolución entre los fieles cristianos. Los expertos han llegado a establecer con ellas hasta cuatro grupos, siendo las lauretanas, utilizadas en la italiana Basílica de la Santa Casa de Loreto, las que han tenido mayor reconocimiento y uso (Fiores y Meo, 1988: 1054-1058). Ello fue posible gracias al Decreto del papa Clemente VIII del año 1601 destinado a eliminar de los manuales devocionales de la época expresiones consideradas poco ortodoxas, permitiendo usar solo las letanías antiguas contenidas en los breviarios, misales, pontificales y rituales, así como las cantadas en el Santuario de Loreto.

Con independencia de ello, la devoción a María y a su Inmaculada Concepción fue motivo para que diferentes religiosos compusieran textos que la ensalzaran, tomando para ello como referencia variados escritos de diversa naturaleza y autoría. Uno de ellos fue el cartujo fray Nicolás de la Iglesia, prior de la cartuja de Miraflores y covisitador para dicha orden en la provincia de Castilla, quien en 1659 publicó en Burgos Flores de Miraflores. Al parecer el libro iba a tener en origen el título de Hieroglificos del Mysterio de la Purisima Concepcion de nuestra Señora, según indica Francisco de Loaysa, prior de la cartuja de Granada, quien cuatro años antes otorgó la licencia de la orden para la publicación. El motivo que llevó al fraile cartujo a redactar el libro fue glorificar a María y difundir los jeroglíficos pintados en su capilla del monasterio burgalés (Escalera Pérez, 2009). Consideraba que si bien en dicho recinto «predicarian las paredes su pureza, y sería mas estimado el sermon hecho por un instrumento mudo», eran pocos los que podrían disfrutarlo, por lo que estimaba

IMAGO, NÚM. 12, 2020, 121-136 
Juan Carlos Hernández Núñez,Alfredo J. Morales

conveniente darlo a conocer mediante la publicación y así poder ver «en boca del mas pobre y rudo Catholico, alabada la Concepción de la Virgen» (Iglesia, 1659, s/p). Tales palabras resultan adecuadas al cometido que cumplen los símbolos marianos de Santa María la Blanca, sirviendo también los jeroglíficos de dicho libro para valorar e interpretar alguno de los «títulos gloriosos» de la «Reyna de los Angeles» pintados en el templo sevillano [fig. 5].

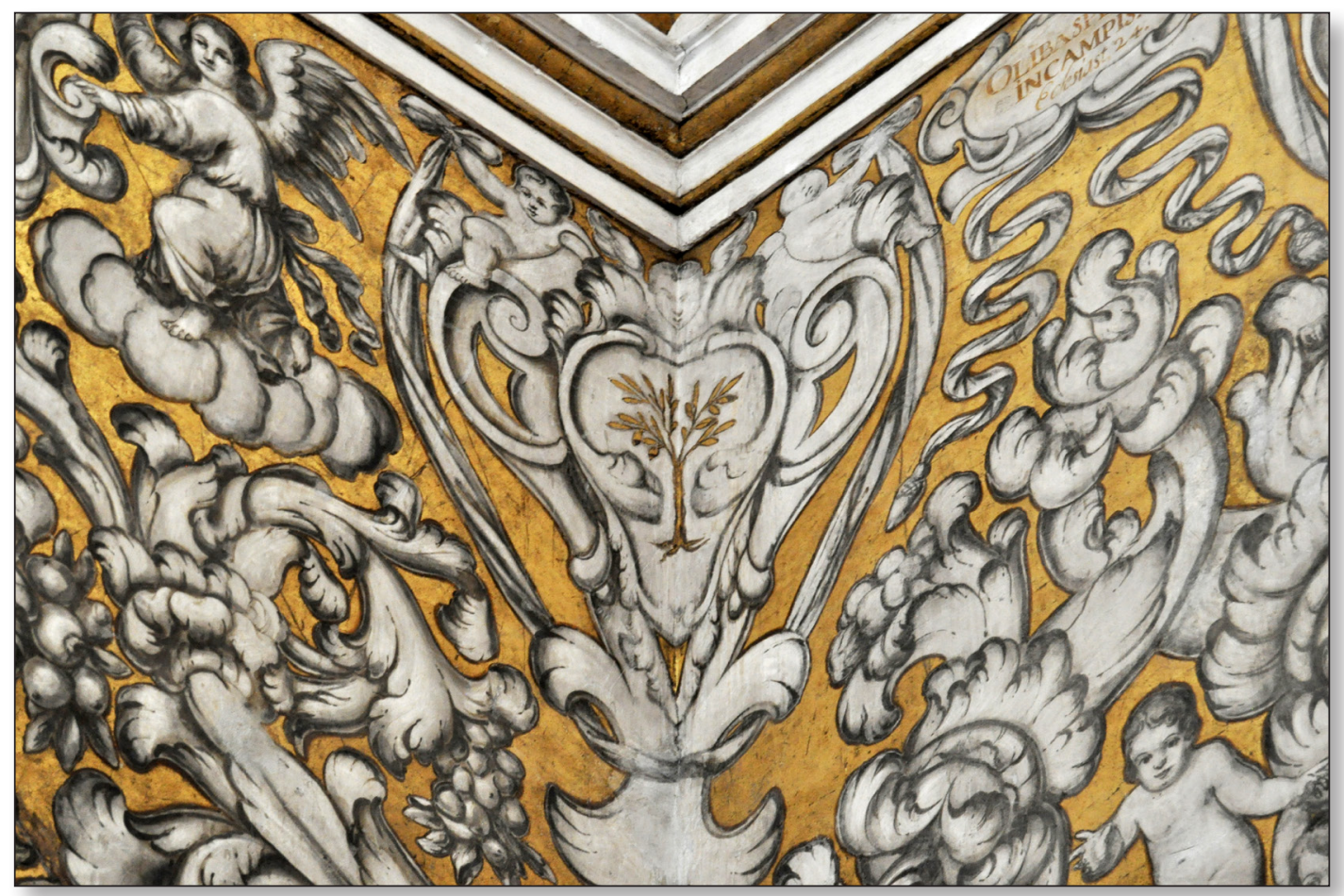

Fig. 5. Olivo. Ángulo nave del evangelio.

En su fachada se sitúa una inscripción latina fechada en 1741 (Aguilar Gutiérrez y Arenillas, 1996) correspondiente al Génesis $(28,17)$, Hic est domus Dei et porta coeli, (Esta es casa de Dios y puerta del cielo), considerada clave para entender el programa del conjunto (Recio Mir, 2015: 193). No obstante, es en el interior donde se ofrece el verdadero sentido de las pinturas del templo, la exaltación de la Concepción Inmaculada de María, resumida en la frase dos veces repetida en el arco del sotocoro. Como se ha señalado, se vale para ello de las letanías de la Virgen expresadas mediante las imágenes y textos distribuidos por las naves laterales de la iglesia. En la del evangelio el primer texto, tomado del Apocalipsis 21,9 y referido a la Jerusalén celestial, se identifica perfectamente con María Veni, ostendam tibi sponsam uxorem Agni, (Ven, que te voy a mostrar a la esposa del cordero). La forma de manifestarla es mediante las representaciones dispuestas en el muro y las enjutas de los arcos formeros, más el cuadro de La Inmaculada Concepción pintado por Murillo, situado en la cabecera de la nave. La primera imagen, un olivo, la alaba como el Oliva speciosa in campis, (Olivo hermoso en la llanura), del (Si. 24,19), apareciendo en la primera enjuta el Arca de Noé y la frase Arcam Domini, Dei Israel, (Arca del Señor, Dios de 
Israel) $(1$ Cro. 15,14$)$. Sigue una palmera con texto perdido, que cabe interpretar con la frase Quasi palma exaltata sum, (como palmera me he elevado) (Si. 24, 18) y una inscripción sobre la mujer apocalíptica identificada como Civitas magna, quae habet regnum super reges terrae, (la gran ciudad, la que tiene la soberanía sobre los reyes de la tierra), (Ap. 17,18). En la tarja frontera está pintado un lirio, aclamándose a María como Lilium inter spinas, (Lirio entre los cardos), (Ct. 2,2). La simétrica ofrece una estrella y el texto la reconoce como Stella matutina in medio nebulae, (Lucero del alba en medio de las nubes) (Si. 50,6) y en otra cartela se la considera Ipsa vero civitas aurum mundum simile vitro mundo, (Ciudad de oro puro semejante al vidrio puro), (Ap. 21,18). La siguiente y mediante un galeón la proclama como Navis in medio mari, (Nave en medio del mar), (Pr. 30,19), mientras la cartela del muro contrario la compara con la Ciudad de Dios y exclama Gloriosa dicta sunt de te, civitas Dei, (Cosas admirables se dicen de ti, Ciudad de Dios), (Sal. 87,3) ${ }^{4}$. En la tarja aovada se la pone en parangón con la luna mediante la frase del Cantar de los Cantares $(6,10)$ Pulchra ut luna, (Hermosa como la luna). Sobre el muro frontero, mediante la vista de una ciudad, se la considera como Ierusalem, quae aedificata est ut civitas, (Jerusalén, construida como ciudad), (Sal. 122,3$)^{5}$ y en la tarja simétrica se pinta el sol y se dice que es Electa ut sol, (Refulgente como el sol), (Ct. 6,10). Las cartelas que harían ángulo en la cabecera de la nave no se han conservado, si bien sobre el arco derecho hay un cartucho con la inscripción Cipresus in monte Sion, (Ciprés en el monte de Sión), (Si. 24,17) ${ }^{6}$, lo que lleva a considerar que en el ángulo inmediato se representaría dicho árbol [fig. 6].

Este conjunto de alabanzas a la Virgen tiene su culminación en el cuadro de La Inmaculada Concepción que representa a María entre nubes y querubines, venerada por un grupo de arrobados devotos que reconocen en Ella a la elegida de Dios, preservada de cualquier pecado desde el comienzo del tiempo (Ángulo Íñiguez, 1981: 335-337; Finaldi, 2012: 113). A ello se refiere la inscripción latina de la filacteria sostenida por unos angelitos en el flanco derecho de la pintura, cuyo texto In principio Dominus dilexit illam, (En principio Dios la amó), es la unión de las primeras palabras del Génesis con otras extraídas del Libro de la Sabiduría $(8,3)$ [fig. 7].

En la nave de la epístola las letanías marianas arrancan de la capilla bautismal. No obstante, en su ingreso e interior hay inscripciones alusivas al sacramento del bautismo, con frases de los evangelios de san Mateo $(3,17)$, Hic est Filius meus dilectus, in quo mihi complacui, (Este es mi Hijo amado, en quien tengo complacencia) y de san Juan (3,5), Nisi quis natus fuerit ex aqua et Spiritu Sancto, non potest introire in regnum Dei, (El que no naciere del agua y del Espíritu Santo, no puede entrar en el reino de Dios). Si bien, claramente vinculadas al bautismo, ambas frases tienen como protagonista al Espíritu Santo, el único que puede purificar y santificar al creyente mediante la Palabra de Dios. Y del paráclito fue templo la propia María, como se indica en unos de los símbolos que aparecen a continuación, por lo que dicha frase es perfectamente adecuada para un programa mariológico [fig. 8].

4. En la cartela se indica que es el Sal.86. Entre la inscripción y el versículo hay una pequeña diferencia en cuanto a la forma verbal.

5. La inscripción latina cita el Sal. 121.

6. En el versículo del Eclesiástico se habla del monte Hermón y no de Sion.

IMAGO, NÚM. 12, 2020, 121-136 


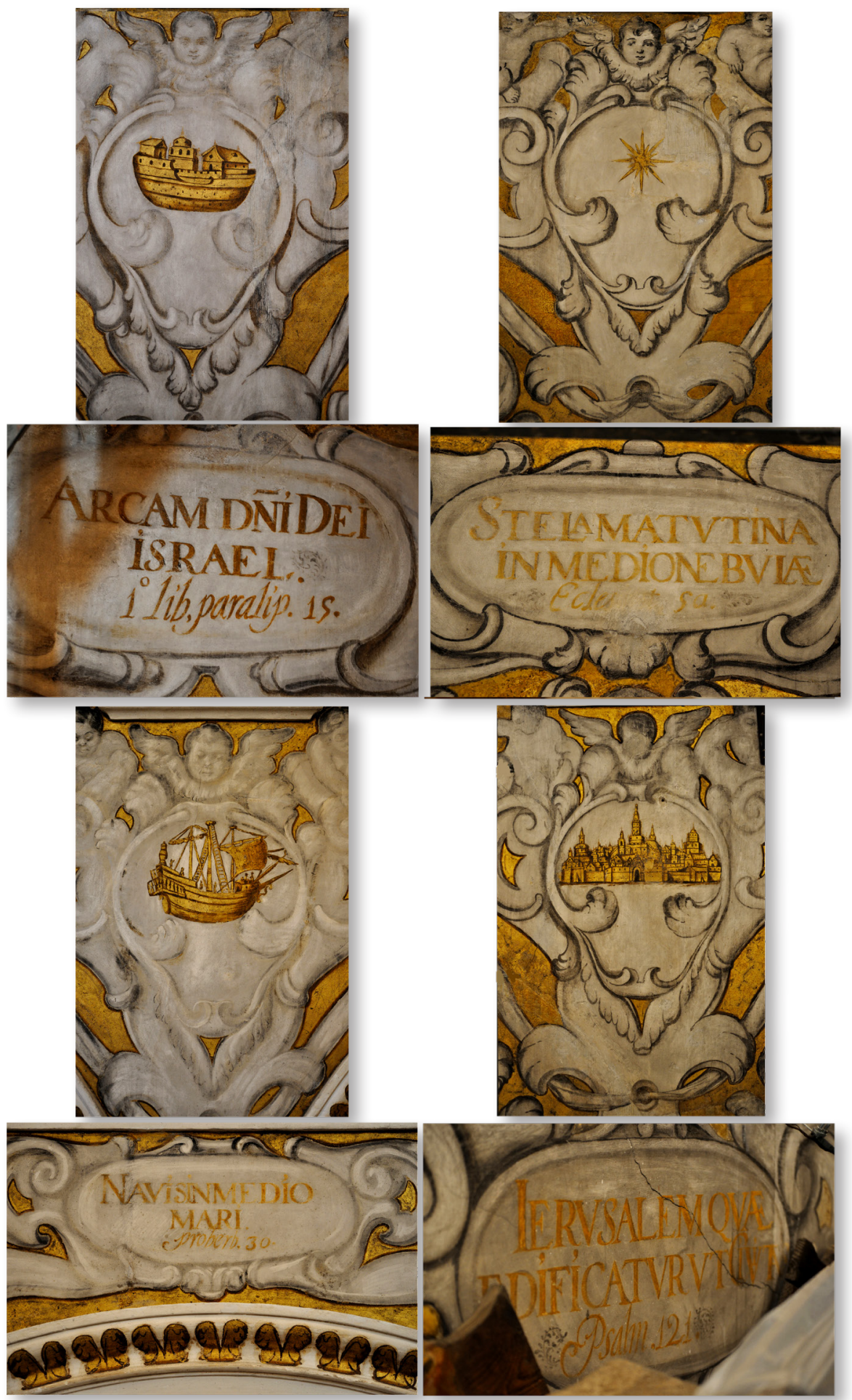

Fig. 6. Símbolos. Nave del evangelio. 

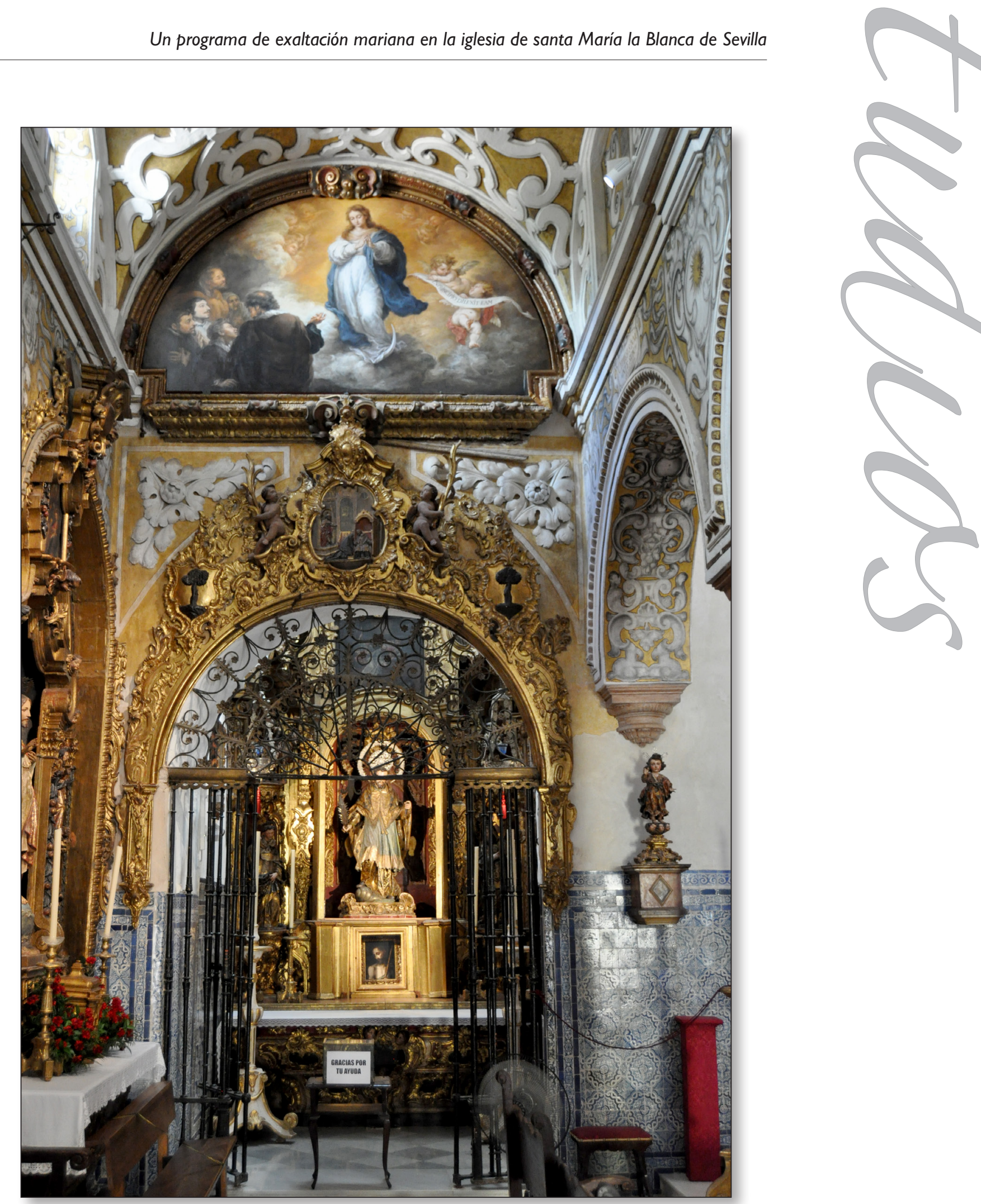

Fig. 7. Inmaculada Concepción. Murillo. Cabecera de la nave del evangelio.

IMAGO, NÚM. I2, 2020, I2I-136 

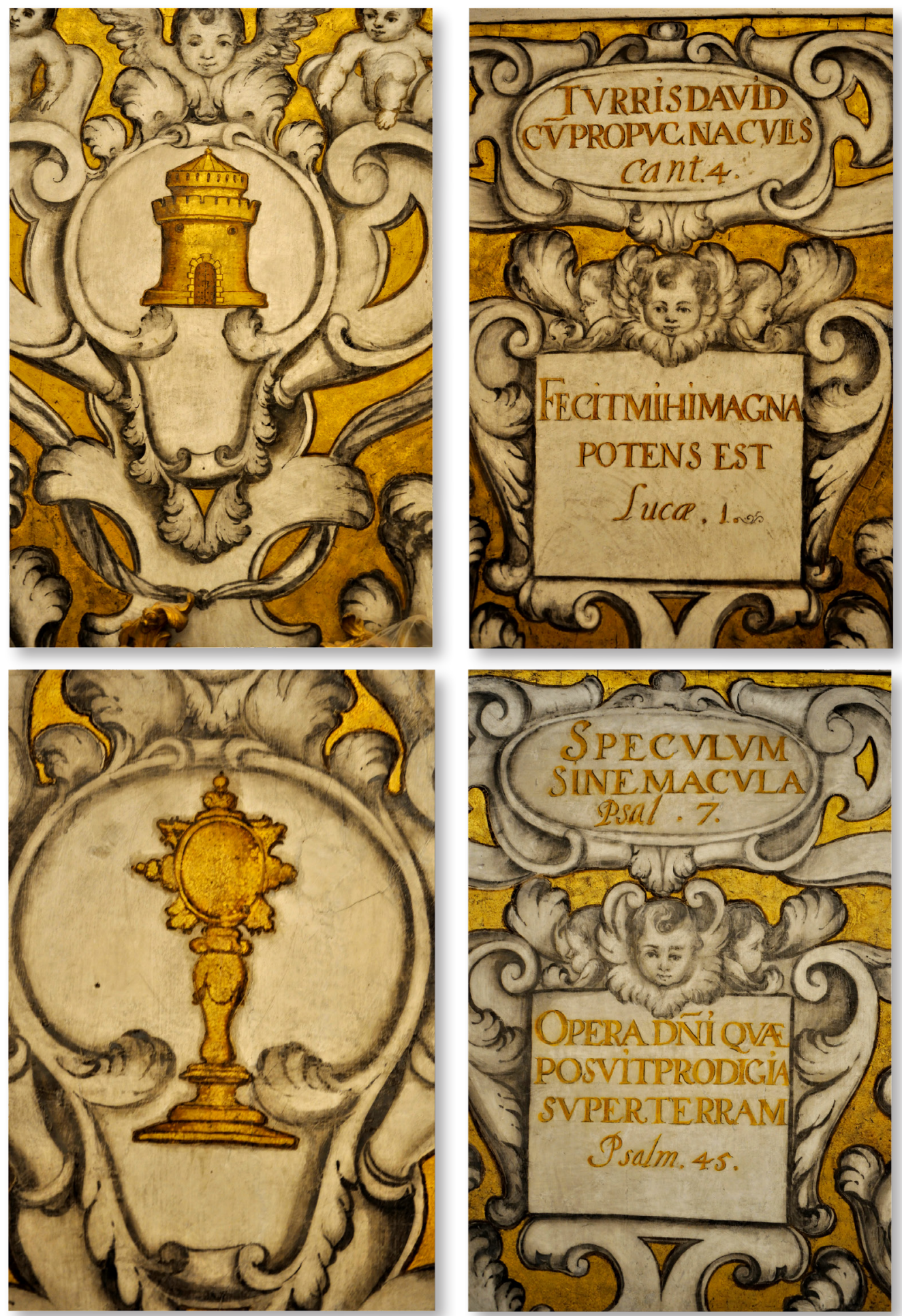

Fig. 8. Símbolos. Pared de la nave de la epístola. 
El texto evangélico de la primera cartela hizo imposible situar en ella la frase del símbolo mariano de la tarja que hace ángulo entre los muros meridional y occidental. Presenta un árbol con sus raíces, cuya interpretación se desconoce, aunque pudiera tratarse del "Árbol de la Vida», jeroglífico quinto en la obra de fray Nicolás de la Iglesia, antes mencionado y que ensalza a María como madre de la vida (Iglesia, 1659: 30v.-32). La tarja simétrica en el arranque de los arcos formeros alberga un rosal y con la leyenda del Eclesiastico $(24,18)$ se la considera Plantatio rosae in Iericho, (Como plantel de rosas en Jericó). En la enjuta inmediata se la llama Hortus conclusus, (Huerto cerrado), (Ct. 4,12). La tarja del muro representa una jarra dorada y el texto que la identifica, tomado de Hebreos $(9,4)$ denomina a María como Urna aurea habens manna (Urna de oro con el maná), aludiendo a que llevó durante nueve meses en su vientre el pan que bajó del cielo y da vida al mundo. Complementariamente, en la cartela cuadrangular la frase de los Salmos $(45,10)$ Astitit regina a dextris tuis in ornata auro, (A tu diestra una reina adornada de oro) ${ }^{7}$, alude a su vida de pureza y de la plenitud de la gracia. Seguidamente, mediante la presencia de una fuente acompañada del texto de Zacarías $(13,1)$, se la muestra como Fons patens domui Iacob, (Fuente abierta para la casa de Jacob) ${ }^{8}$. La imagen simétrica del muro y el texto identificativo procedente del Cantar de los Cantares $(4,4)$ denominan a María Turris David cum propugnaculis, (Torre de David fortificada). Con una frase del Magnificat correspondiente a Lucas $(1,49)$ se resalta como ella misma proclamó que Dios Fecit mihi magna potens est, (Ha hecho en mí grandes obras). En la siguiente enjuta aparece la escalera, acompañada del texto del Génesis $(28,12)$ Scala Iacob, (Escala de Jacob), aludiendo a que María es la escalera por la que se sube a la gracia. El muro frontero ofrece el espejo y dos textos. El primero es del Libro de la Sabiduría $(7,26)$ Speculum sine macula, (Espejo sin mancha) y el segundo del Salmo $(46,9)$ Opera Domini, quae posuit prodigia super terram, (Obra del Señor, que puso prodigios sobre la tierra) ${ }^{9}$, ensalzando la pureza de María por elección de Dios. La siguiente tarja queda oculta por el retablo de la Trinidad, incorporado al ajuar del templo con bastante posterioridad a las pinturas murales. En la enjuta de los arcos fronteros se ha pintado una puerta, identificada por el texto del Génesis $(28,17)$ como Porta Caeli "Puerta del Cielo», aludiendo a que la Pureza de María es la que nos permitirá entrar en el cielo. Casi tapada por el citado retablo está la siguiente tarja del muro, con unas flores chorreantes. Se identifican por el texto y destacan a María como Lilivm distillans myrrham, (Lirios que destilan mirra) (Ct. 5,13). En la enjuta de los arcos se ha pintado un edificio sobrevolado por una paloma, que ensalza a la Virgen como Templum Spiritu Sancti, (Templo del Espíritu Santo), (1 Co. 6,19). Las tarjas de los ángulos de la cabecera están partidas por la mitad, posiblemente porque el retablo con La Última Cena pintada por Murillo que ocupaba el testero de la nave no permitía pintarlas completas. Ante tal situación se optó por dividir la representación del árbol en dos mitades y situar en el muro el cartucho con el texto del Eclesiástico $(24,19)$ que alaba a María como el Platanus exaltata, (Plátano que se ha elevado) [fig. 9].

7. En la inscripción se cita el Sal. 44. Existe una pequeña diferencia, ya que según la inscripción tendría vestidos dorados.

8. El texto bíblico habla de la casa de David.

9. En el primero de los textos se indica que corresponde a los Salmos.

IMAGO, NÚM. 12, 2020, 121-136 


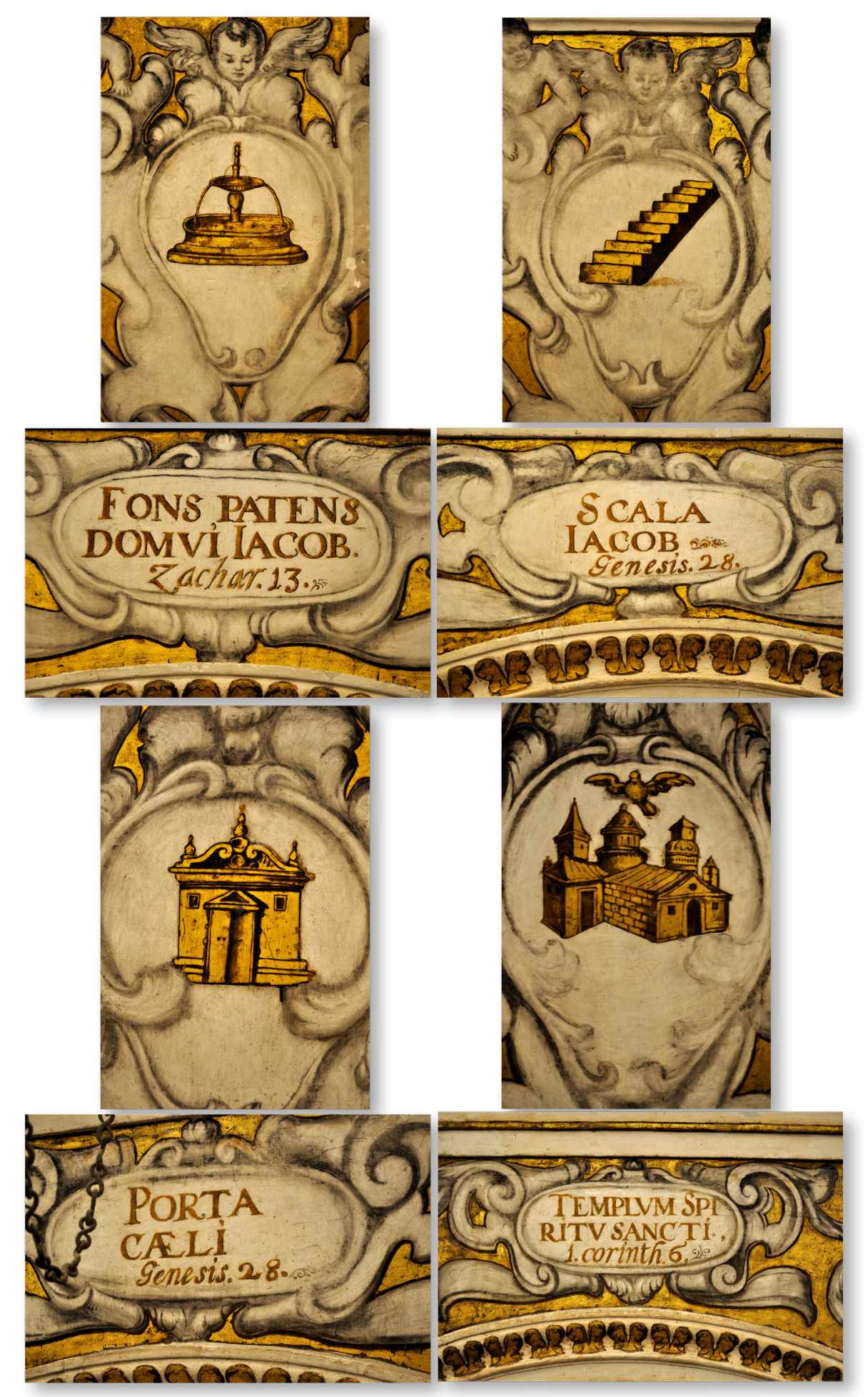

Fig. 9. Símbolos. Enjutas de los arcos formeros. Nave de la epístola. 
Concluye con ello el conjunto de emblemas marianos de la nave de la epístola, si bien no puede olvidarse que su cabecera la presidía el citado lienzo de La Última Cena correspondiente a la capilla del comulgatorio y que sobre el mismo se encontraba la pintura de Murillo de $\mathrm{La} \mathrm{Fe}$. En ella se representa, contemplada por varios personajes, una matrona elevando con su mano derecha un cáliz y la hostia sobre los que desciende el Espíritu Santo, mientras el brazo izquierdo lo apoya sobre las Sagradas Escrituras y porta unas llaves. Tal tipo iconográfico ha llevado a considerar que fuera una alegoría de la Iglesia "como conservadora y administradora de la Eucaristía» (Angulo Íñiguez, 1981: 338-339). Hay, por consiguiente, una clara relación entre ambas pinturas, reforzada por la frase In finem dilexit eos, (Los amó hasta el extremo) escrita en la filacteria que sostiene un ángel en el lienzo superior, correspondiente a Juan $(13,1)$, que el evangelista sitúa antes del lavatorio de los pies y de la cena pascual en la que Cristo instituyó la Eucaristía. Esta frase viene a ser el colofón a «En principio Dios la amó» existente en el lienzo de La Inmaculada Concepción, de

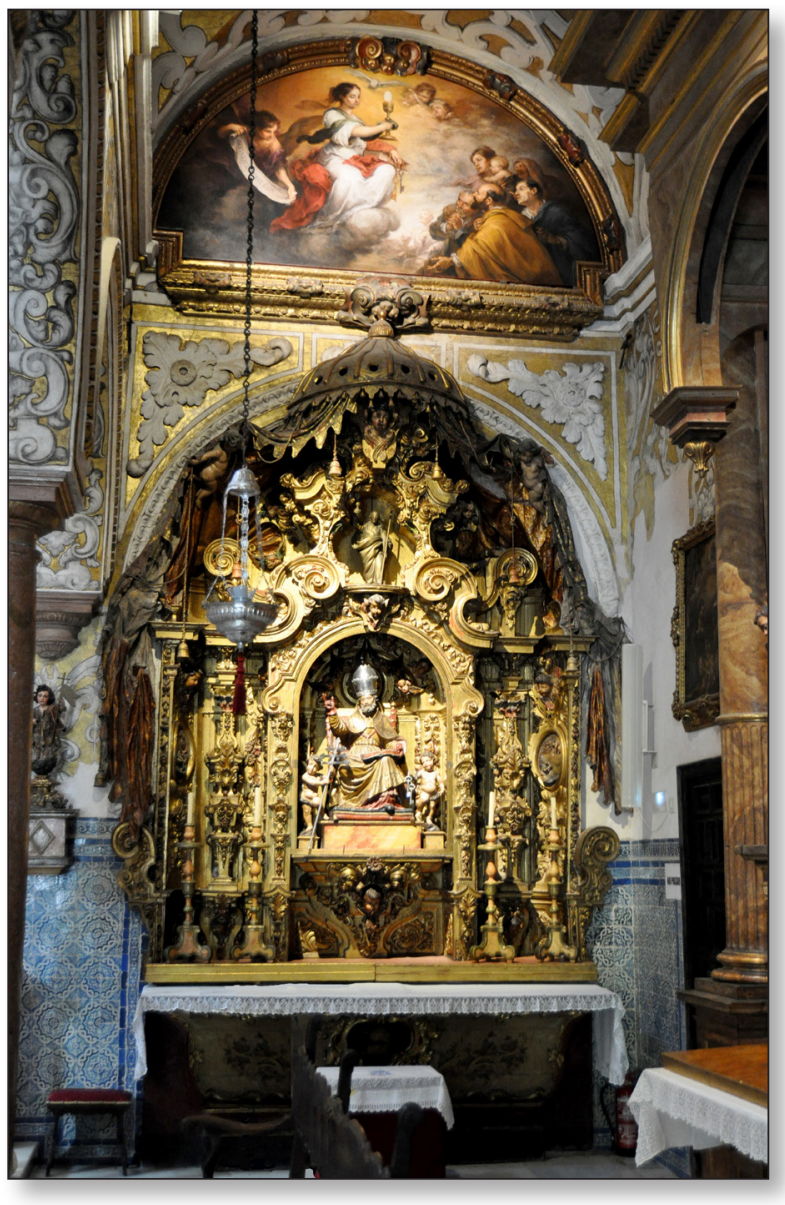

Fig. 10. La Fe. Murillo. Cabecera nave de la epístola. la nave del evangelio. Por otra parte, estos lienzos vienen a reunir las dos grandes devociones populares de la Sevilla del Barroco, la Eucaristía y la Inmaculada. Tal y como recoge Torre Farfán, ambas se expresaron unidas en el nuevo Alabado que abrieron los sermones de las fiestas de consagración del templo en 1665: “Bendito y alabado sea el Santísimo Sacramento del Altar, y la Inmaculada Concepción de la Virgen Santissima N. S. concebida sin mancha de pecado original, en el primer instante de su ser" (Angulo Íñiguez, 1981:338) [fig. 10].

Este extraordinario programa es testimonio de la erudición de su creador el canónigo don Justino de Neve, aunque en ningún momento los documentos y textos contemporáneos lo aclaran. Conociendo su empeño en llevar a cabo la renovación de la iglesia, su decisiva actuación en seleccionar a los artistas encargados de las obras y su munificencia durante el proceso de transformación y fiesta de consagración, es lógico pensar que fuera el inventor del mensaje desplegado en sus muros. Aunque, como se ha señalado, es posible que en la tarea de selección de imágenes y textos contara con la ayuda del licenciado Velázquez Soriano que había sido párroco de la iglesia, pero fallecido en 1665. Con independencia de ello es evidente que la iglesia de Santa María la Blanca es un excepcional ejemplo de la cultura del Barroco y un extraordinario exponente del fervor con el que Sevilla acogió el reconocimiento de la Concepción Inmaculada de María.

IMAGO, NÚM. 12, 2020, I21-136 


\section{BIBLIOGRAFÍA}

Aguilar Gutiérrez, J. y Arenillas, J. A. [1996]. «Las pinturas murales de la fachada de la iglesia de Santa María la Blanca y su restauración», Atrio, 8/9, 37-51.

Angulo Íñiguez, D. [1981]. Murillo. Su vida. Su arte, su obra, Madrid, t. I.

Arenillas, J. A. [2005]. Del clasicismo al barroco. Arquitectura sevillana del siglo XVII, Sevilla.

Bonet Correa, A. [1978]. Andalucía barroca. Arquitectura y urbanismo, Barcelona.

Cenalmor Bruquetas, E. [2012]. "La Inmaculada Concepción de los Venerables», en Finaldi, G. (Ed.), Murillo y Justino de Neve. El arte de la amistad. Catálogo de la Exposición, Madrid, ficha $\mathrm{n}^{\circ}$ 7, 114-117.

Cómez, R. [2015]. Sinagogas de Sevilla. Sevilla.

Escalera Pérez, R. [2009]. “Emblemática Mariana. Flores de Miraflores de fray Nicolás de la Iglesia". Imago. Revista de emblemática e imagen visual, 1, 45-63.

Falcón Márquez, T. [1988]. "La Iglesia de Santa María la Blanca de Sevilla», Laboratorio de Arte, 1, 117-131.

Falcón Márquez, T. [1991]. "Valdés Leal y la arquitectura sevillana», Laboratorio de Arte, 4, 149-168.

Falcón Márquez, T. [2011]. «El canónigo Justino de Neve en la iglesia de Santa María la Blanca de Sevilla», Laboratorio de Arte, 23, 589-598.

Falcón Márquez, T. [2012]. «La iglesia de Santa María la Blanca punto de encuentro entre Murillo y Justino de Neve», en Finaldi, G. (Ed.), Murillo y Justino de Neve. El arte de la amistad, Catálogo de la Exposición, Madrid, 61-71.

Falcón Márquez, T. [2013]. «Pinturas murales y en lienzo de la iglesia de Santa María la Blanca de Sevilla», en Alma Arts. Estudios de Arte e Historia en homenaje al Dr. Salvador Andrés Ordax, Valladolid, 265-272.

Falcón Márquez, T. [2015]. La iglesia de Santa María la Blanca y su entorno, Arte e historia, Sevilla.

Finaldi, G. [2012]. «La Inmaculada Concepción» y «El Triunfo de la Fe», en Finaldi, G. (Ed.), Murillo y Justino de Neve. El arte de la amistad, Catálogo de la Exposición Madrid, 2012, p. 113.

Fiores, S. de y Meo, S. (dirs.) [1988]. Nuevo diccionario de Mariología. Madrid.

Gil Delgado, O. [2013a]. "Una sinagoga desvelada en Sevilla: estudio arquitectónico», Sefarad, 73, 69-96.

Gil Delgado, O. [2013b]. «Santa María la Blanca de Sevilla: templo de tres religiones. Estudio arquitectónico», Archivo Hispalense, 291-293, 65-97.

Iglesia, N. de la [1659]. Flores de Miraflores. Burgos.

Morales, A. J. [2009]. "Yeserías fingidas en la Sevilla de finales del Seiscientos», en Congreso Internacional Andalucía Barroca, t. I, Arte, Arquitectura y Urbanismo. Actas, Bilbao, 147-158.

Morales, A. J. [2019]. "Sobre arquitectura y escultura lígnea: marcos para Murillo», en Navarrete Prieto, B. (coord.). Murillo ante su IV centenario, perspectivas historiográficas y culturales. Universidad de Sevilla, Ayuntamiento de Sevilla. Instituto de la Cultura y de las Artes de Sevilla (ICAS), Sevilla, 167-176.

Recio Mir, A. [2015]. «Fiesta edificada viva y eterna: Justino de Neve, Torre Farfán y algunas claves interpretativas de Santa María la Blanca de Sevilla», Laboratorio de Arte, 27, 185-209.

Roda Peña, J. [2012]. Pedro Roldán escultor 1624-1699. Madrid.

Torre Farfán, F. de la [1666]. Fiestas que celebro la Iglesia Parrochial de Santa Maria la Blanca, capilla de la Sta. Iglesia Metropolitana y Patriarchal de Sevilla..., Sevilla, Juan Gómez de Blas. 